\title{
Tratamento do ceratocisto odontogênico: uma revisão de literatura
}

DOI: $10.46919 / \operatorname{arch} 2 n 3-028$

Recebimento dos originais: 01/01/2021

Aceitação para publicação: 31/03/2021

\author{
Rosa Milene Menezes Lima \\ E-mail: rosamilene.menezes@gmail.com \\ Rafaela Alves Castro \\ João Eudes Teixeira Pinho Filho
}

\section{INTRODUÇÃO}

O Ceratocisto Odontogênico possui características histopatológicas e comportamentos clínicos específicos que resultam em um tratamento agressivo e, muitas vezes, insatisfatório. Por essa razão, devese estudar uma ampla gama de tratamentos e compará-los, e, assim, decidir qual seria o mais adequado para cada paciente, buscando sempre a opção mais conservadora possível.

\section{OBJETIVOS}

Fazer uma revisão das abordagens terapêuticas para o Ceratocisto Odontogênico e estabelecer um comparativo entre esses tratamentos. Revisão de literatura: Foi realizado um levantamento na base de dados PubMed fazendo o uso dos seguintes descritores: tumores odontogênicos, tratamento conservador e recidiva na língua inglesa e portuguesa. Os artigos selecionados compreendem o período de 2015 a 2020. Foram selecionados 47 artigos após leitura de título, resumo e texto completo. A partir disso, foram selecionados 8 artigos para realizar essa revisão de literatura, que demonstram formas de alternativas de tratamento desse tumor.

\section{RESULTADOS}

Dois artigos realizaram a descompressão como tratamento de escolha. Outros dois utilizaram a enucleação e osteotomia como método, e, em um deles, também foi mencionada a possibilidade de uma ressecção cirúrgica e curetagem. Um artigo utilizou apenas a solução de Carnoy como abordagem terapêutica e os demais utilizaram a terapia gênica no tratamento do Ceratocisto Odontogênico. Considerações finais: Portanto, é de suma importância que esta pesquisa demonstre uma diversidade de abordagens terapêuticas para amplificar os conhecimentos sobre o assunto, para que recidivas sejam evitadas e a qualidade de vida do paciente operado seja alcançada. 
Palavras-chaves: Tumores Odontogênicos, Tratamento Conservador, Recidiva. 